\title{
特集 各領域におけるネオアジュバントの位置付け一1
}

\section{切除可能な進行胃癌に対する術前補助化学療法}

\author{
横浜市立大学外科治療学・一般外科 \\ 佐藤 勉 利野 靖 山田六平 大島 貴 \\ 益田 宗孝
}

\section{内容要旨}

ACTC-GCで切除可能な進行胃癌に対する術後補助化学療法としてS-1が標準治療となったが, 層 別化解析でStage IIIに対する有効性は実証されなかった，そこで，予後不良である大型 3 型・4 型胃 癌やbulkyN2胃癌を対象とした術前補助化学療法（Neoadjuvant chemotherapy: NAC）が注目され， 第 II 相試験であるJCOG0210でS-1/CDDP療法の有効性が示され, 現在第 III 相試験であるJCOG0501が 進行中である. しかし, 今までNACの有効性の根拠として考えられてきたMAGIC試験やACCORD-07 試験が, EORTC-04954試験結果から疑問視されてきている.

本邦における切除不能・進行胃癌に対する標準治療はS-1/CDDP療法とされているが, さらなる治 療成績向上のため 3 剂併用療法のDCS療法の第 II 相試験が報告されている. 海外でも 3 剂併用療法

（DCF療法，DXP療法など）の臨床試験結果が報告され，治療成績の向上が期待されている.

NACの治療効果を改善するための候補として 3 剂併用療法の第 II 相試験が数多く計画されている が，JCOG0501の結果を踏まえて 2 剂と 3 剂併用療法の良質な第吕相試験が望まれる.

索引用語：進行胃癌, 術前化学療法, DCS療法

\section{はじめに}

近年, 胃癌の治療成績は, 早期発見と外科手術 の進歩により飛躍的に向上を遂げている。この治 療成績向上の理由として, 本邦においては進行胃 癌に対するD2郭清が標準治療とされ ${ }^{1)}$ ，その根治 切除術の施行率が欧米に比べて格段に高いことが 挙げられる。しかしながら，このように治療成績 が向上している胃癌の中でも, 高度進行胃癌であ る大型 3 型・4型胃癌やbulky N2胃癌においては, 外科切除後の予後は十分とは言えない.

胃癌の予後を肉眼的分類で見てみると，びまん 浸潤型である 4 型胃癌が最も不良であると言われ ているが ${ }^{2)} ３$ 型胃癌の予後は直径が大きくなる

第36回日本外科系連合学会学術集会シンポジゥム 6 連絡先 佐藤 勉

厂 236-0004 神奈川県横浜市金沢区福浦 3-9

横浜市立大学付属病院外科治療学 - 一般外科
につれて不良となり, 病理組織学的腫瘍径が 4 〜 $8 \mathrm{~cm}$ で 5 年生存率が $37.0 \%, 8$ 12 cmで $20.3 \%$, $12 \mathrm{~cm}$ を超えると $0 \%$ であった ${ }^{3)}$. 同様に, Roviello らは再発率が 4 ～ $8 \mathrm{~cm}$ の場合は $61 \%, 8 \mathrm{~cm}$ 以上 の場合は $82 \%$ と, 腫瘍サイズと再発との関係を報 告している ${ }^{4)}$.

一方, 腹腔動脈や総肝動脈周囲に転移リンパ節 が集塊を形成するbulky N2胃癌においては, D2郭 清のみでは根治切除が困難であり, 胃切除を行っ た後でも微小遠隔転移を伴っている場合が多く， その治療成績は十分満足いくものではない( ${ }^{5)}$ ７). 以上より, $8 \mathrm{~cm}$ 以の大型 3 型胃癌, 4 型胃癌や bulky N2胃癌においては手術単独での治療成績 は十分ではないと考えられた。

そのため, これらの対象においてょり郭清度の 高い手術や術後補助化学療法の検討が成されてき たものの, D2郭清を伴う手術治療を凌駕する結果 は得られていない. そこで, 大型 3 型・ 4 型胃癌 
Table 1 Phasell trials of neoadjuvant chemotherapy for local advanced gastric cancer

\begin{tabular}{|c|c|c|c|c|}
\hline Study & Criteria & Protocol & Primary EP & $\mathrm{pRR}(>\operatorname{Gr} 1 \mathrm{~b})$ \\
\hline $\begin{array}{l}\text { JCOG0001 } \\
\text { Br J Surg 200911) }\end{array}$ & $\begin{array}{l}\text { Bulky N2 and/or } \\
\text { paraaortic LN } \\
\text { metastasis }\end{array}$ & $\begin{array}{c}\mathrm{CPT}-11 / \mathrm{CDDP} \\
\times 2-3 \rightarrow \mathrm{OP}\end{array}$ & $\begin{array}{c}\text { OS, } \\
\text { Incidence of TRD }\end{array}$ & $15 \%$ \\
\hline JCOG0002 & & & & \\
\hline Gastric cancer 200912) & Type4 & $\mathrm{S}-1 \times 2 \rightarrow \mathrm{OP}$ & $2 y O S$ & $33 \%$ \\
\hline $\begin{array}{l}\text { JCOG0210 } \\
\text { ASCO GI 2006 }\end{array}$ & $\begin{array}{l}\text { Type } 4 \text { or } \\
\text { Large Type3 }\end{array}$ & $\mathrm{SP} \times 2 \rightarrow \mathrm{OP}$ & $\begin{array}{c}\text { Propotion of protocol } \\
\text { achievement, } \\
\text { Incidence of TRD }\end{array}$ & $48 \%$ \\
\hline $\begin{array}{l}\text { JCOG0405 } \\
\text { ASCO GI 2008 }\end{array}$ & $\begin{array}{l}\text { Bulky N2 and/or } \\
\text { paraaortic LN } \\
\text { metastasis }\end{array}$ & $\mathrm{SP} \times 2-3 \rightarrow \mathrm{OP}$ & $\%$ R0 resection & $51 \%$ \\
\hline $\begin{array}{l}\text { JACCRO GC-01 } \\
\text { EJSO 2010'5) }\end{array}$ & $\begin{array}{l}\text { cT3-4, NO-3, MO } \\
\text { (JCGC) }\end{array}$ & $\mathrm{SP} \times 1 \rightarrow \mathrm{OP}$ & Feasibility, Safety & $39 \%$ \\
\hline
\end{tabular}

JCOG : Japan Clinical Oncolgy Group, JCGC : Japanese Classification of Gastric Carcinoma, LN : lymph node, CDDP : Cisplatin, SP : S-1/CDDP, OS:Over all survival, TRD : Treatment related death

PbulkyN2胃癌を対象とした術前補助化学療法

(Neoadjuvant chemotherapy: NAC) が注目さ れ, 第 II 相試験であるJCOG0210でS-1/CDDP療法 の有効性が示され，現在第 III 相試験である JCOG0501が進行中である.

今回, 当教室で行ってNACとして行ったDCS療 法の臨床試験成績について解析し, 進行胃癌に対 するNACに関する報告を整理しその位置付けを 検討した.

\section{進行胃癌に対する術前補助化学療法の意義}

ACTS-GCによりStage II / III 胃癌に対する術 後補助化学療法を加えることの有用性が示され, 進行胃癌に対する治療は術後 1 年間のS-1投与が 標準的治療となった ${ }^{8)}$. しかし, 層別化解析からは Stage II 胃癌では術後補助化学療法の意義はある ものの, Stage III 胃癌の治療成績は満足いくもの ではない ${ }^{9)}$. また, 術後補助化学療法ではコンプラ イアンスが保てないなどの問題点もある ${ }^{10)}$.

そこで, 進行胃癌のさらなる治療成績の向上の ため, NACが期待される治療として取り上げられ, 現在様々な第 II 相, 第吕相試験が進行中である.

NACは「胃癌治療ガイドライン」第 3 版におい て「臨床研究としての治療法」と位置付けられて いる. NACは術後補助化学療法に比べて, 以下の 利点が挙げられる. (1)術後に比ベコンプライアン スが高く, より強力な化学療法が可能, (2)早期に 遠隔微小転移に対する治療を開始でき, 根治を目
指せる可能性がある, (3)腫瘍局所における血管構 築が破壊されていないため薬剤の到達性が良好で あろうと推測される，(4)リンパ節転移などが縮小 しDown stagingによる根治度の高い手術が可能 となるとともに機能温存手術が可能となり, 術後 のQOLの向上につながる可能性がある, (5)原発巣 による化学療法の効果判定が可能であり, 術後補 助化学療法の参考になる, (6)癌細胞の活動性を下 げ, 手術操作による癌細胞の散布転移を抑制する.

その一方でNACの欠点としては, (1)手術時期が 遅れる, (2)抗癌剤不応症例では治療中に癌の増大 が起こる可能性がある, (3)抗癌剤による副作用に より耐術能を低下させる可能性がある, (4)入院期 間の延長により医療費の加算が生じる, などが挙 げられる。

\section{術前補助化学療法に求められる条件，本邦・海外 の報告}

NACの欠点を考慮した場合, 治療レジメンに求 められる条件は, (1)短期間で高い奏効率が得られ る，(2)副作用による手術時期への影響がなく保険 診療内で使用できる, (3)コンプライアンスが良く, 外来で完遂可能で，たとえ入院するとしても短期 間で済む，などが挙げられる。

未だ, NACの有効性に関するエビデンスは存在 しない現在, NACに用いることができる治療レジ メンとしては, 切除不能胃癌で高い奏効率を上げ たものが候補となる．本邦において，1998年より 
切除可能な進行胃癌に対する術前補助化学療法

Table 2 Phaselll trials of neoadjuvant chemotherapy for resectable advanced gastric cancer

\begin{tabular}{|c|c|c|c|c|c|c|c|}
\hline Study & Criteria & Protocol & ADJ & $\begin{array}{c}\text { D2 dissection } \\
\text { rate }\end{array}$ & Primary EP & $\begin{array}{l}\text { OS(5-year rate) } \\
\text { Surgery Alone }\end{array}$ & $\begin{array}{c}\text { OS(5-year rate) } \\
\text { NAC }\end{array}$ \\
\hline $\begin{array}{l}\text { MAGIC trial } \\
\text { NEJM 2006'16) }\end{array}$ & $\begin{array}{l}\text { Stage II, III } \\
\text { cT1-T3, cM0 }\end{array}$ & $\mathrm{ECF} \times 3 \rightarrow \mathrm{OP}$ & $E C F \times 3$ & $43.7 \%$ & os & $23 \%$ & $36 \%$ \\
\hline $\begin{array}{l}\text { ACCORD07 } \\
\text { JCO 2011 }\end{array}$ & $\begin{array}{l}\text { Resectable } \\
\text { cMO }\end{array}$ & $\mathrm{FP} \times 2-3 \rightarrow \mathrm{OP}$ & $\mathrm{FP} \times 3-4$ & N.D. & os & $24 \%$ & $38 \%$ \\
\hline $\begin{array}{l}\text { EORTC\#04954 } \\
\text { JCO 201018) }\end{array}$ & $\begin{array}{l}\text { UICC } \\
\text { Stage III and } \\
\text { IV, cMO }\end{array}$ & $\begin{array}{c}\mathrm{FP}+\mathrm{d}-\mathrm{L}-\text { folinic acid } \times 2 \\
\rightarrow \mathrm{OP}\end{array}$ & None & $95.7 \%$ & os & $48 \%$ & $52 \%$ \\
\hline $\begin{array}{l}\text { JCOG0501 } \\
\text { Ongoing }\end{array}$ & $\begin{array}{l}\text { Type4 and } \\
\text { Large Type3 }\end{array}$ & $\mathrm{SP} \times 2 \rightarrow \mathrm{OP}$ & $\begin{array}{c}S-1 \\
1 y\end{array}$ & Ongoing & os & Ongoing & Ongoing \\
\hline
\end{tabular}

EP : Endpoint, ADJ : adjuvant chemotherapy, OS : Over all survival, NAC : neoadjuvant chemotherapy, SP : S-1/CDDP, FP : 5-FU/ CDDP, ECF : Epirubicin/5-FU/CDDP, N.D. : Not described

Japan Clinical Oncology Group(JCOG)を中心とし て, 胃癌に適応のあるCPT-11, Cisplatin (CDDP), TS-1（S-1）といった薬剤を用いての術前化学療 法の検討が行われた（Table 1).

bulky N2/\#16胃癌を対象としたJCOG-0001で はCPT-11/CDDP療法の有用性が検討されたが, 有害事象により主要評価項目の一つである治療関 連死において統計学的に仮説を証明できず，治療 レジメンの変更が余儀なくされた ${ }^{11)}$.

4 型胃癌を対象としてS-1単独療法の有用性を 検証したJCOG0002では ${ }^{12)}$, 安全面では問題なく施 行できたものの, 治療効果において，2年生存割 合が59\%と仮説の $60 \%$ を上回ることができなかっ たため, より有効な治療法が求められ, 以降の試 験ではTS-1/CDDP療法（SP療法）が選択される こととなった.

bulky N2胃癌においてもSP療法の検討がなさ れた ${ }^{13)}$.JCOG0405では，対象が同様なJCOG0001 と比較して, 奏効率や組織学的奏効割合といった 効果や安全性で優れた結果が示され, SP療法は有 効な治療法であると考えられた. 以上より, 現時 点での本邦における胃癌NACの至適レジメンは, SP療法が第一候補と考えられる.

根治切除可能な $8 \mathrm{~cm}$ 以上の大型 3 型 / 4 型胃 癌に対するSP療法の検討を行ったJCOG0210では, 治療完遂割合が73\%, 原発巣に対する病理学的奏 効率 $49 \%$, 治療関連死 $2 \%$ と良好なコンプライア ンスの維持と有効率と安全性が示されている ${ }^{14)}$. また, cT3-4 胃癌にNACとしてSP療法 1 コース
施行後に切除を行うJACCRO GC-01試験におい て治療完遂割合は $94 \%$, 治療関連死，再手術率は $0 \%$, 病理学的奏効率 $39 \%$ と良好な有効率と安全 性が報告されている ${ }^{15)}$.これらの結果を元に, 現 在, 術前化学療法未施行群との無作為化比較臨床 第 III相試験（JCOG0501）が進行中である.

進行胃癌に対するNACが治療成績の改善に寄 与すると考えられてきた根拠として, 海外に実施 されてきたMAGIC 試験 ${ }^{16)}$ やACCORD-07試験 ${ }^{17)}$ において術前化学療法施行群の予後が手術単独群 に比較して有意に改善したことが挙げられてき た.しかし, 2010年にEORTC-04954試験 ${ }^{18)}$ の試験 結果が報告されそれぞれの試験結果を比較する と, 手術単独群における 5 年生存率はMAGIC試験 で23\%, ACCORD-07試験で24\%, EORTC-04954 試験で約 $48 \%$ となっており, EORTC-04954試験 のようにD2リンパ節郭清の精度が高ければ手術 単独群の予後が大きく改善することが示された. 一方, 術前化学療法群の 5 年生存率はMAGIC 試 験で $36 \%$, ACCORD-07試験で $38 \%$, EORTC04954試験で約 $52 \%$ となっている. EORTC-04954 試験ではD2リンパ節郭清率は $95.7 \%$ と高率であり, NAC群と手術単独群の生存率に有意差を認めな かった。これらの結果から, NACの論拠として用 いられてきたMAGIC 試験やACCORD-07試験の 結果は, 不十分なリンパ節郭清に留まった手術単 独群 (MAGIC 試験のD2リンパ節郭清率43\%)の予 後が不良であったためにNAC群との間に有意な 予後の差が得られただけであるという可能性が示 
Table 3 Phasell/III trials of triplet chemotherapy for advanced gastric cancer

\begin{tabular}{|c|c|c|c|c|c|}
\hline Study & Criteria & Regimen & & $\mathrm{RR}$ & $\mathrm{AE}(>\mathrm{Gr} 3)$ \\
\hline $\begin{array}{l}\text { DCF vs CF (V325), Phase III } \\
\text { JCO 2006 }\end{array}$ & $\begin{array}{l}\text { Unresectable or } \\
\text { recurrent }\end{array}$ & $\begin{array}{l}\text { DOC }: 75 \mathrm{mg} / \mathrm{m}^{2} \\
\text { CDDP }: 75 \mathrm{mg} / \mathrm{m}^{2} \\
5-F U: 750 \mathrm{mg} / \mathrm{m}^{2}\end{array}$ & $\begin{array}{l}\text { (day1) } \\
\text { (day1) } \\
\text { (day1-5) } \\
\text { days/course }\end{array}$ & $37.0 \%$ & $\begin{array}{l}\text { Leukopenia } 65 \% \\
\text { Neutropenia } 82 \% \\
\text { Nausea } 14 \% \\
\text { Diarrhea } 19 \%\end{array}$ \\
\hline $\begin{array}{l}\text { DCS, Phase II } \\
\text { Cancer Chemo Pharm 201030) }\end{array}$ & $\begin{array}{l}\text { Unresectable or } \\
\text { recurrent }\end{array}$ & $\begin{array}{l}\mathrm{DOC}: 60 \mathrm{mg} / \mathrm{m}^{2} \\
\text { CDDP }: 60 \mathrm{mg} / \mathrm{m}^{2} \\
\mathrm{~S} 1: 80 \mathrm{mg} / \mathrm{m}^{2}\end{array}$ & $\begin{array}{l}\text { (day8) } \\
\text { (day8) } \\
\text { (day1-14) } \\
\text { days/course }\end{array}$ & $87.1 \%$ & $\begin{array}{l}\text { Leukopenia } 64.5 \% \\
\text { Neutropenia } 77.4 \% \\
\text { Anorexia } 35.5 \%\end{array}$ \\
\hline $\begin{array}{l}\text { DCS (KDOG0601), Phase II } \\
\text { Cancer Chemo Pharm 201129) }\end{array}$ & $\begin{array}{l}\text { Unresectable for } \\
\text { M1(JCGC) }\end{array}$ & $\begin{array}{l}\mathrm{DOC}: 40 \mathrm{mg} / \mathrm{m}^{2} \\
\mathrm{CDDP}: 60-70 \mathrm{mg} / \mathrm{m}^{2} \\
\mathrm{~S} 1: 80 \mathrm{mg} / \mathrm{m}^{2}\end{array}$ & $\begin{array}{l}\text { (day1) } \\
\text { (day1) } \\
\text { (day1-14) } \\
\text { days/course }\end{array}$ & $81.3 \%$ & $\begin{array}{l}\text { Leukopenia } 22 \% \\
\text { Neutropenia } 41 \% \\
\text { Anorexia } 5 \%\end{array}$ \\
\hline $\begin{array}{l}\text { DXP, Phase II } \\
\text { Ann Surg Oncol 201027) }\end{array}$ & $\begin{array}{l}\text { Unresectalbe because of } \\
\text { local invasion or intra- } \\
\text { abdominal metastasis }\end{array}$ & $\begin{array}{l}\text { DOC }: 60 \mathrm{mg} / \mathrm{m}^{2} \\
\text { CDDP }: 60 \mathrm{mg} / \mathrm{m}^{2} \\
\text { Capecitabine : } 1875 \mathrm{mg} / \mathrm{m}^{2} \\
21\end{array}$ & $\begin{array}{l}\text { (day1) } \\
\text { (day1) } \\
\text { (day } 1-14) \\
\text { days/course }\end{array}$ & $65.0 \%$ & $\begin{array}{l}\text { Leukopenia } 28 \% \\
\text { Neutropenia } 52 \% \\
\text { Vomiting } 0 \% \\
\text { Hand-foot } 0 \% \\
\end{array}$ \\
\hline $\begin{array}{l}\text { DXP, Phase I/II } \\
\text { Cancer Chemo Pharm 201128) }\end{array}$ & $\begin{array}{l}\text { Unresectalbe or } \\
\text { recurrent }\end{array}$ & $\begin{array}{l}\text { DOC }: 60 \mathrm{mg} / \mathrm{m}^{2} \text { day } 1 \\
\text { CDDP }: 60 \mathrm{mg} / \mathrm{m}^{2} \text { day } 1 \\
\text { Capecitabine : } 2250 \mathrm{mg} / \mathrm{m}^{2} \\
21\end{array}$ & $\begin{array}{c}\text { day } 1-14 \\
\text { days/course }\end{array}$ & $68.0 \%$ & $\begin{array}{l}\text { Leukopenia } 40 \% \\
\text { Neutropenia } 62.5 \% \\
\text { Nausea } 12.5 \% \\
\text { Vomiting } 17.5 \% \\
\end{array}$ \\
\hline
\end{tabular}
Docetaxel/CDDP/5-FU, CF : CDDP/5-FU, DOC : Docetaxel, CDDP : Cisplatin

唆される. 切除可能な進行胃癌に対するNACの第 III相試験に関する報告を一覧とした（Table 2 ）．

術前の化学療法を行うことの確固たる根拠がな い現在, 本邦においても手術単独群に比較して術 前化学療法群の予後が改善するか否かの第 III相臨 床試験を早急に進めることが肝要であり, 臨床試 験以外で安易に術前化学療法を行うことには慎重 になるべきと考えている。

\section{2 剤 vs 3 剂併用療法}

進行・再発胃癌に対する化学療法はS-1, CDDP, CPT-11, DOC, Paclitaxelなどの導入により新た なレジメンが開発され，第正相試験も複数行われ ているが，まだエビデンスにそしく統一された治 療戦略は存在しない.わが国ではJCOG9205, JCOG9912，SPIRITSなどの第 III 相試験の結果か ら5-FUに対するS-1の非劣性, S-1に対するS-1+ CDDPの優劣性が証明され, S-1+CDDPが標準治 療と位置付けられ広く行われている ${ }^{19) \sim 211}$. また S-1のパートナーとしてDOC, Paclitaxel, CPT11をそれぞれ使用した第 III相試験が本邦で進行中 であり, GC0301/TOP-002試験ではS-1+CPT-11 併用療法のS-1単剂に比べた優劣性は証明できな かった ${ }^{22}$. S-1+DOC併用療法の優劣性を検証する JACCRO GC-03試験は登録が終了し最終解析結
果を待つ段階にある ${ }^{23)}$.

海外では, 進行胃癌に5-FU/CDDP併用療法に Docetaxel（DOC）を上乗せしたDOC/CDDP/5FU併用（DCF）療法が現在注目を集めている. V325試験はDCF療法とCDDP/5-FU (CF) 療法と を比較した第 III 相試験であり, 奏効率はDCF群 $36.7 \%$, CF群 $25.4 \%$, 無増悪期間中央值（Disease Free Survival: DFS) はDCF群5.6力月, CF群3.7 力月, 生存期間中央值 (Median Survival Time: MST）はDCF群9.2力月, CF群8.6力月といずれに おいてもDCF療法が有意差を持って有効である と報告された ${ }^{24)}$.

本邦においては，DCF療法の5-FU持続静注を より投与が簡便である経口剤のS-1に置き換えた $\mathrm{DOC} / \mathrm{CDDP} / \mathrm{S}-1$ 併用 (DCS) 療法が検討されて いる．5-FUをS-1に置き換えることにより，さら なる抗腫瘍効果の増強や副作用の軽減, 点滴時間 の短縮の可能性があり, 有用性の高い治療法の一 つとなることが期待される。 また, 韓国でS-1を Capecitabineに置き換えたDOC/CDDP/Xeloda （DXP）併用療法の第 II 相試験結果が報告されて いる ${ }^{25)}$ (26).

切除不能進行・再発胃癌に対するDCS療法の第 II 相試験に関する報告は投与量の若干の違いはあ 
切除可能な進行胃癌に対する術前補助化学療法

Talbe 4 Adverse events during chemotherapy in all eligible patients $(n=13)$

\begin{tabular}{lcccccc}
\hline & Grade 0 & Grade 1 & Grade 2 & Grade 3 & Grade 4 & $>$ Grade 3(\%) \\
\hline Hematological toxicity & & & & & & \\
Leukopenia & 4 & 1 & 3 & 4 & 1 & $38.4 \%$ \\
Neutropenia & 3 & 1 & 3 & 4 & 2 & $46.1 \%$ \\
Febrile neutropenia & 12 & - & - & 1 & 0 & $7.7 \%$ \\
Anemia & 8 & 4 & 0 & 1 & 0 & $7.7 \%$ \\
Thrombocytopenia & 12 & 0 & 0 & 0 & 1 & $7.7 \%$ \\
Nonhematological toxicity & & & & & & \\
Creatinine & 9 & 4 & 0 & 0 & 0 & $7.7 \%$ \\
Stomatitis & 5 & 6 & 1 & 1 & 0 & $7.7 \%$ \\
Anorexia & 1 & 5 & 1 & 6 & 0 & $46.1 \%$ \\
Nausea & 1 & 5 & 1 & 6 & 0 & $46.1 \%$ \\
Diarrhea & 9 & 1 & 1 & 2 & 0 & $15.4 \%$ \\
Pigmentation & 5 & 7 & 1 & 0 & 0 & $0.0 \%$ \\
Thromboembolic event & 12 & 0 & 0 & 1 & 0 & $7.7 \%$ \\
Alopecia & 0 & 10 & 3 & - & - & - \\
\hline
\end{tabular}

るが, 小泉らが奏効率 $87.1 \%$, MST 660 日 $^{27)}$, 佐 藤らが奏効率 $81.3 \%$, MST 687 日 $^{28)}$ といずれもSP 療法より高い奏効率を報告している.

NACの有効性を改善する目的で高い奏効率が 報告されている 3 片併用療法に期待がされてお り，現在様々な第 II 相試験が計画・進行中である

(Table 3 ).

\section{当教室での第 II 相試験（DCS療法）}

\section{1. 対象と方法}

cStage II, III と診断された腫瘍最大径 $8 \mathrm{~cm}$ 以 上の大型 3 型・4 型病変またはbulkyN2の症例を 対象とし，第 II 相試験を計画した。2009年 9 月か ら症例登録を開始した。化学療法開始前に全例全 身麻酔下に審査腹腔鏡を施行され，POCY0を確認 したのちにDCS療法 2 コースを施行. 治療終了後 2 週以内に胃切除を行い, 術後 1 年間の補助化学 療法（S-1）を行うプロトコールとした.

投与量・スケジュールはKDOG0601のレジメン を使用した. S-1 80mg / $\mathrm{m}^{2}$ の14日間連日経口投与 (day1-14) とday1にDOC $40 \mathrm{mg} / \mathrm{m}^{2}$ に加えて CDDP $60 \mathrm{mg} / \mathrm{m}^{2}$ を投与した. 休薬期間は 2 週間 とした.

Primary endpointは病理学的奏効割合, Secondary endpointを全生存期間, 無再発生存期間, 根 治切除割合, 奏効率, 治療関連死, 合併症発生率 とし, 目標症例数 30 例で登録を開始した.

\section{2. 治療成績}

2011年10月までに13例が症例登録されDCS療 法を開始した. そのうち 12 例が胃切除まで到達し,
11例が病理組織結果が判明している。平均年齢は 71.7歳, 男性11名, 女性 2 名であった。 NACが終 了した12例のうち, 術前画像評価による胃癌取り 扱い規約, RECIST (Response Evaluation Criteria In Solid Tumors）基準による効果判定で奏効率は 58.3\%（7/12）であった．有害事象により 2 例が DCS療法を 1 コース終了後に切除した. NACを 2 コース完遂し, 原病の増悪なく手術を完了できた プロトコール完遂率は $83.3 \%(10 / 12)$ であった. 化学療法の有害事象はCTCAEver4.0で評価を行 い, 発生率をGrade別にまとめた（Table 4).

手術術式は, 胃全摘10例, 幽門側胃切除 2 例で, 全例D2郭清を施行した. 組織の線維化に伴いリン パ節郭清などで手術の難易度が上がり，手術時間 がやや延長し出血量も増加する傾向が見られたが, 重篤な術中・術後合併症を認めておらず平均術後 在院期間は10.3日（7 - 18日）であった. DCS療 法の明らかなデメリットは認めず, 全例で根治度 B以上の手術が可能であった。 病理組織学的奏効 率（Grade 1b以上）は45.4\%（5/11）であった. 観察期間中央值は419日 (74-824日). 12例中 1 例に 再発を認めたが, 残る11例は無再発生存中である.

\section{おわりに}

切除可能進行胃癌に対する術前化学療法は高い 奏効率と, 安全性が得られれば有望な治療の一つ となりうると考えられる。しかし，NACのエビデ ンスが確立されていない現状では, JCOG0501に おいてNACの有効性を示す結果が出ることを待 ち, 良質な 2 剂vs 3 剂併用療法の第 III 層臨床試験 
において治療成績の向上が検証されるべきであ る. 3 剂併用療法の候補としてDCS療法も有望な レジメンの一つとして期待される.

\section{文 献}

1) Sano T, Sasako M, Yamamoto $S$, et al: Gastric cancer surgery : morbidity and mortality results from a prospective randomized controlled trial comparing D2 and extended para-aortic lymphadenectomy-Japan Clinical Oncology Group study 9501. J Clin Oncol $22: 2767-2773,2004$

2）岡島一雄：胃癌患者の予後因子一多変量解析によ る検討一. 日消外会誌 30 : 別冊, 1997

3）笹子三津留, 丸山圭一, 木下 平, 他: 胃癌に扔け る術前化学療法をどう評価するか一適応の選択と 治験の設定について一. 消外 $15 ：$ 159-167, 1992

4) Roviello F, Marrelli D, Manzoni G. de, et al: Prospective study of peritoneal recurrence after curative surgery for gastric cancer. Br J Surg $90: 1113-1119,2003$

5）久保義郎, 栗田 啓, 石㠃雅浩, 他：2 群リンパ 節転移陽性胃癌の治療方針. 日臨外会誌 63 : 550-555, 2002

6）柴崎信一, 木田晴海, 媣海清人, 他 : 第 2 群リン パ節転移陽性胃癌における転移リンパ節個数お よび総肝動脈幹リンパ節転移の予後因子として の意義. 日消外会誌 $32: 1962-1968,1999$

7）岩瀬弘明, 島田昌明, 中村元典, 他：TS-1/CDDP 併用療法にてCRが得られたBulky N2および大動 脈周囲リンパ節転移を伴う 3 型スキルス胃癌の 1 例. 癌と化療 $29: 1817-1821,2002$

8) Sakuramoto S, Sasako M, Yamaguchi T, et al: Adjuvant chemotherapy for gastric cancer with S-1, an oral fluoropyrimidine. N Engl J Med 357:1810-1820, 2007

9) Sasako M, Sakuramoto S, Katai H, et al:FiveYear Outcomes of a Randomized Phase III Trial Comparing Adjuvant Chemotherapy With S-1 Versus Surgery Alone in Stage II or III Gastric Cancer. J Clin Oncol 29:4387-4393, 2011

10) Yoshikawa $T$, Tsuburaya A, Morita $S$, et al: A comparison of multimodality treatment: two or four courses of paclitaxel plus cisplatin or S-1 plus cisplatin followed by surgery for locally advanced gastric cancer, a randomized Phase II trial (COMPASS). Jpn J Clin Oncol 40:369-372,
2010

11) Yoshikawa $T$, Sasako M, Sano $T$, et al: A phase II study of preoperative chemotherapy with irinotecan and cisplatin followed by gastrectomy with D3 dissection for gastric cancer with extensive lymph node metastasis: Final results of JCOG0001. Proc Am Soc Clin Oncol Abstract: \#40, 2007

12) Kinoshita $T$, Sasako M, Sano $T$, et al: Phase II trial of S-1 for neoadjuvant chemotherapy against scirrhous gastric cancer (JCOG 0002). Gastric Cancer 12:37-42, 2009

13) Gastric Surgery Group in Japanese Clinical Oncology Group, Kawashima Y, Sasako M, et al: Phase II study of preoperative neoadjuvant chemotherapy (CX) with S-1 plus cisplatin for gastric cancer (GC) with bulky and/or para-aortic lymph node metastases: A Japan Clinical Oncology Group Study (JCOG0405). Proc Am Soc Clin Oncol Abstract: \#118

14) Fujitani K, Sasako M, Iwasaki $Y$, et al: A phase II study of preoperative chemotherapy (CX) with S-1 and cisplatin followed by gastrectomy for clinically resectable type 4 and large type 3 gastric cancer: JCOG 0210. Proc Am Soc Clin Oncol Abstract: \#4609, 2007

15) Yoshikawa T, Omura K, Kobayashi O, et al:A phase II study of preoperative chemotherapy with S-1 plus cisplatin followed by D2/D3 gastrectomy for clinically serosa-positive gastric cancer (JACCRO GC-01 study). Eur J Surg Oncol 36:546-551, 2010

16) Cunningham $D$, Allum $W H$, Stenning SP, et al: Perioperative chemotherapy versus surgery alone for resectable gastroesophageal cancer. N Engl J Med 355:11-20, 2006

17) Ychou M, Boige V, Pignon JP, et al: Perioperative chemotherapy compared with surgery alone for resectable gastroesophageal adenocarcinoma: an FNCLCC and FFCD multicenter phase III trial. J Clin Oncol 29:1715-1721, 2011

18) Schuhmacher C, Gretschel S, Lordick F, et al: Neoadjuvant chemotherapy compared with surgery alone for locally advanced cancer of the stomach and cardia:European Organisation for Research and Treatment of Cancer randomized 
trial 40954. J Clin Oncol 28:5210-5218, 2010

19) Koizumi W, Narahara H, Hara $T$, et al : $S-1$ plus cisplatin versus $\mathrm{S}-1$ alone for first-line treatment of advanced gastric cancer (SPIRITS trial) : a phase III trial. Lancet Oncol 9:215-221, 2008

20) Ohtsu A, Shimada Y, Shirao K, et al: Randomized phase III trial of fluorouracil alone versus fluorouracil plus cisplatin versus uracil and tegafur plus mitomycin in patients with unresectable, advanced gastric cancer : The Japan Clinical Oncology Group Study (JCOG9205). J Clin Oncol $21: 54-59,2003$

21) Boku N, Yamamoto S, Fukuda H, et al: Fluorouracil versus combination of irinotecan plus cisplatin versus S-1 in metastatic gastric cancer: a randomised phase 3 study. Lancet Oncol 10 : 1063-1069, 2009

22) Narahara H, Iishi H, Imamura H, et al : Randomized phase III study comparing the efficacy and safety of irinotecan plus S-1 with S-1 alone as firstline treatment for advanced gastric cancer (study GC0301/TOP-002). Gastric Cancer $14: 72-80,2011$

23) Fujii $\mathrm{M}$ : Chemotherapy for advanced gastric cancer: ongoing phase III study of S-1 alone versus $\mathrm{S}-1$ and docetaxel combination (JACCRO GC03 study). Int J Clin Oncol 13 : 201-205, 2008
24) Van Cutsem E, Moiseyenko VM, Tjulandin S, et al: Phase III study of docetaxel and cisplatin plus fluorouracil compared with cisplatin and fluorouracil as first-line therapy for advanced gastric cancer : a report of the V325 Study Group. J Clin Oncol 24:4991-4997, 2006

25) Sym SJ, Chang HM, Ryu MH, et al : Neoadjuvant docetaxel, capecitabine and cisplatin (DXP) in patients with unresectable locally advanced or metastatic gastric cancer. Ann Surg Oncol 17 : 1024-1032, 2010

26) Kang YK, Ryu MH, Yoo C, et al:Phase I/ II study of a combination of docetaxel, capecitabine, and cisplatin (DXP) as first-line chemotherapy in patients with advanced gastric cancer. Cancer Chemother Pharmacol $67: 1435-1443,2011$

27) Koizumi W, Nakayama N, Tanabe S, et al:A multicenter phase II study of combined chemotherapy with docetaxel, cisplatin, and S-1 in patients with unresectable or recurrent gastric cancer (KDOG 0601). Cancer Chemother Pharmacol 69:407-413, 2011

28) Sato $Y$, Takayama $T$, Sagawa $T$, et al : Phase II study of $\mathrm{S}-1$, docetaxel and cisplatin combination chemotherapy in patients with unresectable metastatic gastric cancer. Cancer Chemother Pharmacol $66: 721-728,2010$ 


\title{
Neoadjuvant Chemotherapy of Resectable Advanced Gastric Cancer
}

\author{
Tsutomu Sato, Yasushi Rino, Roppei Yamada, Takashi Oshima \\ and Munetaka Masuda \\ Department of Surgery, Yokohama City University
}

\begin{abstract}
A subanalysis of the ACTC-GC trial revealed no benefit of postoperative chemotherapy with S-1 in stage III gastric cancer. Neoadjuvant chemotherapy (NAC) for resectable advanced gastric cancer has thus been studied to improve survival. The JCOG0210 trial (a phase II study) showed that NAC with S-1 plus cisplatin was beneficial in resectable advanced gastric cancer, and a phase III study (JCOG0501) is ongoing. The results of the MAGIC trial and ACCORD-07 trial have shown that NAC is effective for advanced gastric cancer, but this has been questioned by the results of the EORTC-04954 trial. S-1 plus cisplatin is currently standard therapy for advanced or unresectable gastric cancer in Japan. However, several regimens have been proposed for triplet therapy, such as docetaxel, cisplatin, and S-1 (DCS), docetaxel, capecitabine (Xeloda), and cisplatin (DXP), and docetaxel, cisplatin, and 5-flurorouracil (DCF). Triplet therapy is expected to improve outcomes in unresectable or advanced gastric cancer. After the results of the JCOG0501 trial become available, phase III trials comparing doublet therapy with triplet therapy will be needed.
\end{abstract}

Key words: advanced gastric cancer, docetaxel, cisplatin, S-1, neoadjuvant chemotherapy 